\title{
Robust Perceptual Wavelet Packet Features for Recognition of Continuous Kannada Speech
}

\author{
Mahadeva Swamy ( $\square$ mahadevaswamy@vvce.ac.in ) \\ Vidyavardhaka College of Engineering https://orcid.org/0000-0003-4891-1236 \\ D J Ravi \\ Vidyavardhaka College of Engineering
}

\section{Research Article}

Keywords: Wavelet Packet Decomposition, Acoustic Models, Hidden Markov Model and Deep Neural Networks.

Posted Date: June 14th, 2021

DOI: https://doi.org/10.21203/rs.3.rs-247034/v1

License: (1) This work is licensed under a Creative Commons Attribution 4.0 International License. Read Full License

Version of Record: A version of this preprint was published at Wireless Personal Communications on July 21st, 2021. See the published version at https://doi.org/10.1007/s11277-021-08736-1. 


\title{
Robust Perceptual Wavelet Packet Features for Recognition of Continuous Kannada Speech
}

\author{
Mahadevaswamy ${ }^{1}$, D J Ravi ${ }^{2}$ \\ ${ }^{1}$ Research Scholar, Department of Electronics and Communication Engineering \\ ${ }^{2}$ Professor, Department of Electronics and Communication Engineering \\ ${ }^{1,2}$ Vidyavardhaka College of Engineering, Mysuru, Visvesvaraya Technological \\ University, Karnataka, India \\ ${ }^{1}$ mahadevaswamy@vvce.ac.in, ${ }^{2}$ ravidj@vvce.ac.in, \\ ${ }^{I}$ Orcid ID: 0000-0003-4891-1236 ${ }^{2}$ Orcid ID: 0000-0002-5758-5893
}

\begin{abstract}
An ASR system is built for the Continuous Kannada Speech Recognition. The acoustic and language models are created with the help of the Kaldi toolkit. The speech database is created with the native male and female Kannada speakers. The $75 \%$ of collected speech data is used for training the acoustic models and 25\% of speech database is used for the system testing. The Performance of the system is presented interms of Word Error Rate (WER). Wavelet Packet Decomposition along with Mel filter bank is used to achieve feature extraction. The proposed feature extraction performs slightly better than the conventional features such as MFCC, PLP interms of WRA and WER under uncontrolled conditions. For the speech corpus collected in Kannada Language, the proposed features shows an improvement in WRA of $1.79 \%$ over baseline features.
\end{abstract}

KEYWORDS: Wavelet Packet Decomposition, Acoustic Models, Hidden Markov Model and Deep Neural Networks.

\section{INTRODUCTION}

The frequent pauses between the speech sounds of a speech signal portrays its unique characteristic that distinguishes it from all other signals. The speech database created in uncontrolled conditions of the environment must be processed to implement a robust automatic speech recognition system. Speech is an important and efficient tool of communication. The speech research drawn the attention of infinite researchers and has emerged as one of the important 
multidisciplinary research areas in the recent decades. Speaker Independent Speech recognition is the task of identifying the spoken word or sentence irrespective of the speaker. The speech recognition has been performed over the several languages. The UNESCO atlas of the world languages danger report-2009, describes that about 197 Indian languages are in critical situation of being extinct. According to Indian census report Percentage of people speaking local languages has drastically reduced[1]. Speech recognition system is implemented for Assamese Language. The vocabulary size is 10 Assamese words, The task of speech recognition is achieved using Hidden Markov Model, I-vector technique and Vector quantization technique. A 39-dimensional features are derived using Mel Frequency Cepstral Coefficients, Delta-Coefficients, Acceleration Coefficients. The Novel Fusion technique outperforms the conventional techniques such as Hidden Markov Model, I-Vector Techniques and Vector Quantization Technique by achieving speech recognition accuracy of 100\%[1]. The ASR system developed and evaluated using a moderate Bengali speech. Then 39-dimensional features are extracted and used to train triphone based HMM technique. The system was able to achieve an accuracy of 87.30\%[2]. The speech recognition system is developed for Bangla accent. The Mel LPC features and their delta. The HMM modeling, lead to $98.11 \%$ recognition accuracy [3]. A Hindi isolated word recognition system is realized with LPC features and HMM Modeling and an accuracy of $97.14 \%$ was achieved corresponding to the word "teen" [4]. Another isolated word recognition system was realized with MFCC features and HTK Toolkit for Hindi language. An accuracy of $94.63 \%$ and a WER of $5.37 \%$ was achieved [5]. A connected word speech recognition system for Hindi language was proposed using MFCC features and HTK Toolkit. An accuracy of $87.01 \%$ was achieved [6].

An isolated digit recognition system was designed using MFCC features and HTK Toolkit for Malayalam isolated words to achieve an 
accuracy of 98.5\% [7]. LPCC, MFCC, Delta-MFCC, Acceleration coefficients and vector quantization is utilized to build a speaker identification system to yield an accuracy of $96.59 \%$. There is boost in the performance of the system by $3.5 \%$ accuracy during testing stage with a consideration to text dependent system[8]. An automatic language identification task is achieved among five Indian languages. The languages selected were are Hindi, Kannada, Telugu and Tamil. All the utterances are created from five native female speakers and five native male speakers. The cepstral features are derived from the speech signals and vector quantization technique based on the codebook concept is used to achieve the task of classification. The system achieved an recognition accuracy of $88.10 \%$ in recognizing spoken Kannada sentences[9]. A word recognition system was built for Punjabi language. The LPC feature vectors were extracted from speech signals. The vector quantization and Dynamic time warping techniques were used for implementing the speech recognition system. Experiments were carried out for different code book sizes from 8 to 256 . The system was able to achieve a accuracy of $94 \%[10]$.

A speaker recognition system was developed for two speech databases. One speech database is created using microphone speech and other speech database is telephone speech. MFCC features are used with the Linear discriminant Analysis technique, Co-variance Normalization, used to train the support vector machines classifier and cosine distance scoring[11]. The speech signal is a complex signal has information of vocal tract and the excitation source. To extract the excitation source information, the Linear Prediction Residual subjected to processing. The LP residual, Phase and Magnitude components are processed at three different levels, segmental level, sub-segmental level and suprasegmental level to derive the language specific excitation source information. The Gaussian Mixture Models are used to perform the classification task[12]. The literature re- 
veals that the Kannada ASR system has not been experimented with Perceptual Wavelet Packet features so far. This approach is one of the first over Kannada language by augmenting the implementation of Perceptual Wavelet Packet features over the Kaldi toolkit. The organization of the article is as follows: In section 1 and 2 provides introductory information towards automatic speech recognition and some of the important works presented in the literature. Section 3 describes about feature extraction methods.

\section{RELATED WORKS}

The automatic speech recognition (ASR) system is able to provide $100 \%$ accuracy under clean environment. But, its performance is degrades significantly when the spoken utterances gets contaminated by the presense of background noise or mismatch in acoustic features extracted from noisy or clean condtions [13, 14, 15] and mismatch in the labelled speech data used to train the classifier [16]. Hence, the performance of ASR system is constrained by two choices namely, correct labelling of speech data and selection of acoustic features. The well known acoustic features for speech recognition is Mel-frequency cepstral coefficients (MFCCs). MFCCs are extracted from the Mel filter banks[17]. MFCCs are obtained using short time Fourier transform (STFT). The mel cepstral coefficients are computed by allowing speech signal to pass through a bank triangular shaped filters having passbands slightly overlapping with adjacent passbands and to obtain a smooth spectrum[18,19]. Spectrum is subjected variations as the impact of background noise increases[18,20]. The popular MFCC technique consists of STFT. The STFT has a requirement that the signal to be processed must be stationary over short interval of time i.e.,semiperiodic signals[21]. Due to the trade-off between time-frequency resolution, it is not easy to detect phones that happen with a rapid burst in a slowly changing signal $[22,18,20]$. This problem of timefrequency resolution is alleviated by using wavelet transform(WT) 
$[23,24,25]$. The major benefit of using wavelet transform is that, unlike using single fixed sized analysis window in STFT, it uses windows with variable duration. The high frequency portion of the speech signal is processed by the short duration window, whereas the low frequency part of the speech signal is processed by the long duration window[24,26-27]. Thus by applying wavelet transform to a speech signal, it can be inspected for the presense or absence of sudden burst (stop phonemes) in a slowly changing signal[20,22]. The conventional wavelet filter bank performed well for phoneme recognition tasks[20]. Because of the fixed resolution of frequency in time-frequency plane, the STFT was not able to find voiced stop due to their characteristic of rapid burst at higher frequencies[20,22]. Multi-resolution potential of wavelets was enormously utilized by many research professionals for feature extraction and demonstrate their benefit for several applications such as, Biomedical application like ECG[28,29], Speech enhancement[30, 31], EEG[32, 33] and Phoneme recognition[20,22,34].

\section{METHODOLOGY}

\subsection{PREPOROCESSING}

The preprocessing functions like framing, windowing and preemphasis are applied to all the wave files in speech database. The frame duration and frame overlap are choosen as $20 \mathrm{msec}$ and $10 \mathrm{mes}$ respectively, for performing framing and windowing.

\subsection{PROPOSED FEATURES}

The Multi-resolution property of the wavelet makes it appropriate tool for handling nonstatinary and semi-stationary signals. This transform can detect unvoiced sounds in the speech signal and it provides best desnoising characteritics. In the recent years, several feature extraction approaches have been invented for speech recognition in uncontrolled environment. But, majority of these feature extraction schemes use Fourier transform to compute the spectrum. 
The speech signal consist of voiced (periodic) and unvoiced (aperiodic) portions throughout its existence. It's a popular fact that the STFT or windowed Fourier transform has fixed and uniform frequency resolution with respect to the time frequency plane. Therefore it is difficult for the methods relay on STFT to recognize sudden bursts in the slowly time varying speech signals. To problem is alleviated by the application of wavelet transforms in the speech recognition research [35,36,37,43-47]. The wavelet transform offers good frequency resolution.

\subsubsection{Theoretical Background of Wavelet Transforms}

Multi Resolution Analysis is an alternative way to STFT technique to analyze a signal. A mathematical scaling function is utilized to obtain a series of approximations to the signal. This principle has been considered by Wavelet Transforms (WT). A comparision of time- frequency resolution between STFT and WT is shown in Figure 1.

\subsubsection{Continuos Wavelet Transform (CWT)}

CWT of a signal $\mathrm{x}(\mathrm{t})$ is given by

$$
\operatorname{CWT}_{x}^{\Psi}(\tau, s)=\frac{1}{\sqrt{s}} \int_{-\infty}^{\infty} x(t) \Psi^{*\left(\frac{t-\tau}{s}\right)} d t
$$

From equation (17), the result of transformation is function of two variables, $\tau$ and $s$ that describe the translation and scaling factor respectively, and $\Psi(\mathrm{t})$ is mother wavelet.
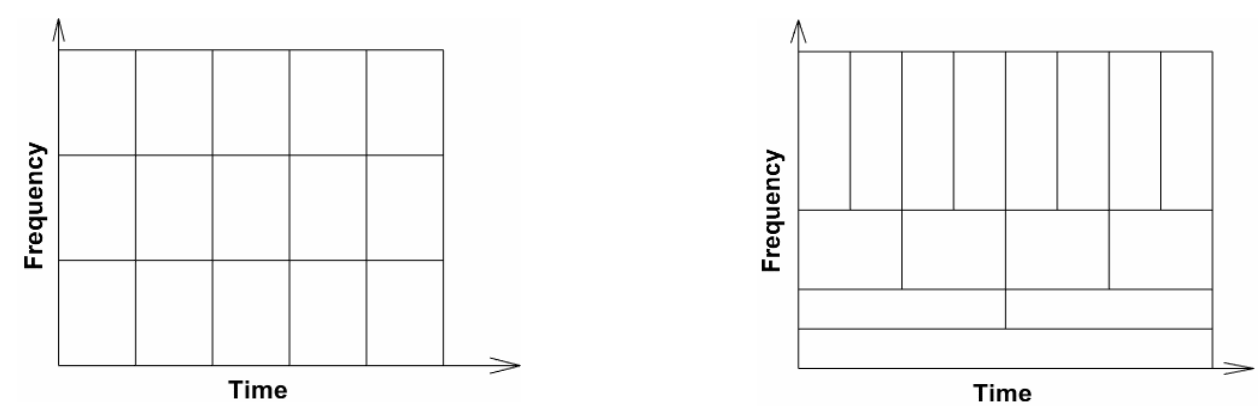

Fig. 1 Comparision of STFT with WT 
The term wavelet is concatenation of two words 'wave' and 'let'. Here wave is signal and let is short. The mother wavelet acts as a model or prototype to derive other window functions. The time information is captured by the variable $\tau$ and the parameter $s$ specifies dialation or compression operation on the wavelet.

\subsubsection{Discrete Wavelet Transform (CWT)}

The CWT is more complicated for signal analysis, because it involves significant computational resources. While DWT is less complicated in capture the signal information effectively[49]. The DWT of signal $\mathrm{x}(\mathrm{t})$ is defined as:

$$
\operatorname{DWT}(j, k)=\frac{1}{\sqrt{\left|2^{j}\right|}} \int_{-\infty}^{\infty} x(t) \psi\left(\frac{t-2^{j} k}{2^{j}}\right)
$$

Mallat successfully demonstrated the method of wavelet decomposition by allowing a signal to pass through a series arrangement of low pass filter and high pass filter pairs. The multi resolution analysis of a signal is shown in Figure $2 \mathrm{a}$ and $2 \mathrm{~b}$ shown below. Here, $h_{0}(n), h_{1}(n)$ in the decomposition tree are low pass and high filter pairs respectively. Similarly $g_{0}(n), g_{1}(n)$ form the low pass and high pass filter pair in the reconstruction tree. 


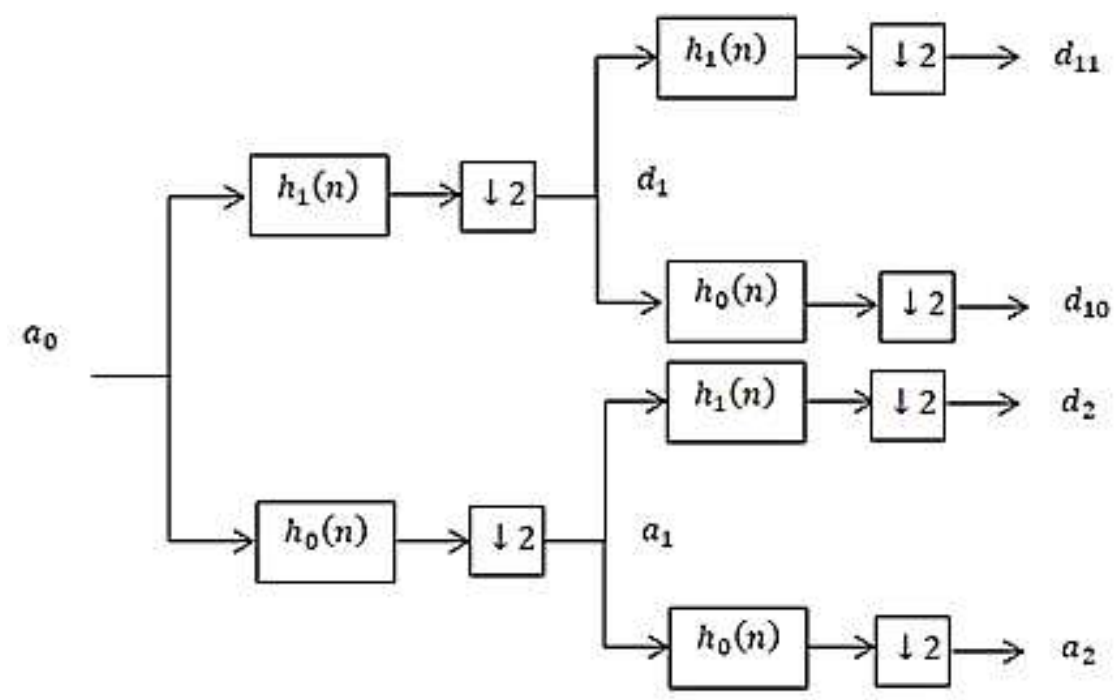

Fig. 2a The balanced 2-level analysis wavelet tree structure for $a_{0}$

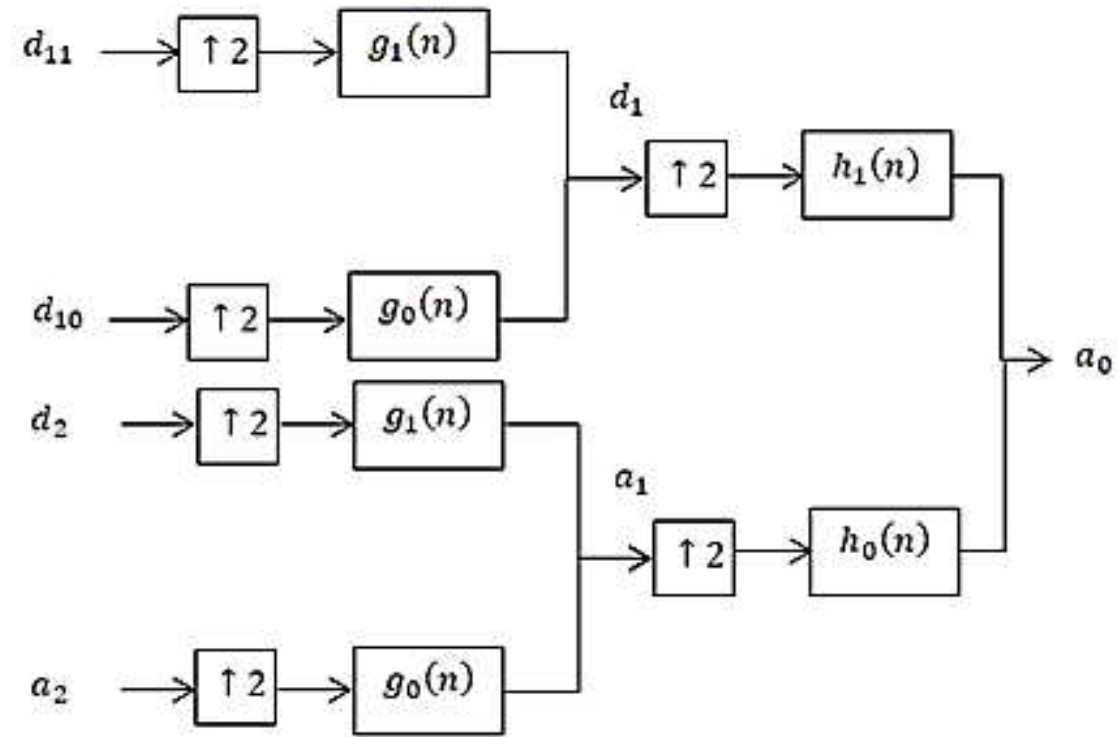

Fig. 2b The balanced 2-level synthesis wavelet tree structure for $a_{0}$ 


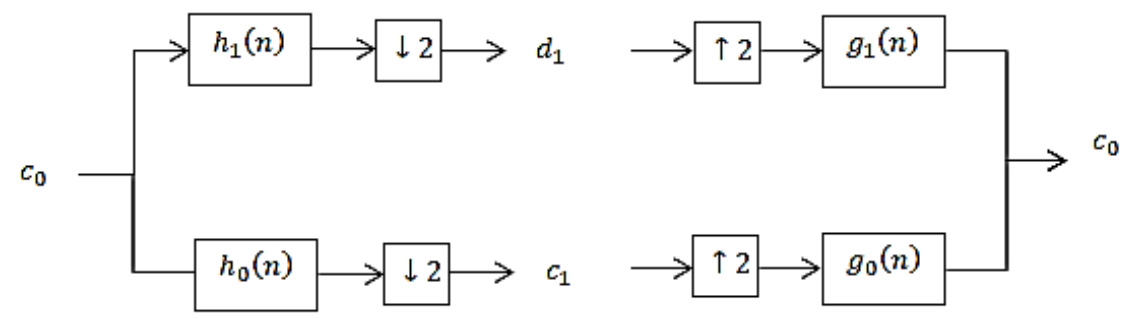

Fig. 3a The one level wavelet analysis and synthesis.

$h_{0}(n)$ and $h_{1}(n)$ are a pair filters used for analysis, whereas $g_{0}(n)$ and $g_{1}(n)$ form another pair of low, highpass filters respectively. These four filters have related as

$$
\begin{aligned}
& h_{1}(n)=(-1)^{n} g_{0}(1-n), \\
& g_{1}(n)=(-1)^{n} h_{0}(1-n)
\end{aligned}
$$

Also, the symbols $\downarrow 2$ and $\uparrow 2$ presented in Figure $2 \mathrm{a}$ and $2 \mathrm{~b}$, denote the decimating and interpolating opertions carried out by a factor of 2 respectively. A pair of one level analysis and synthesis trees are shown in Figure 3. In Figure 3, $\left\{c_{0}(n)\right\} n \in Z$ is the input applied the one level analysis and synthesis tree respectively[23].

$$
\begin{aligned}
& c_{1}(k)=\sum_{n} h_{0}(n-2 k) c_{0}(n) \\
& d_{1}(k)=\sum_{n} h_{1}(n-2 k) c_{0}(n)
\end{aligned}
$$

where $c_{1}(k)$ and $d_{1}(k)$ are known as the approximation space and the detail space respectively. These are created by the one level wavelet analysis of $c_{0}(n)$. The corresponding synthesis tree is shown in Figure 3 can be operated as

$$
c_{0}(m)=\sum_{k}\left[g_{0}(2 k-m) c_{1}(k)+g_{1}(2 k-m) d_{1}(k)\right]
$$




\subsubsection{Wavelet based acoustic feature extraction}

By repeating the iterative decomposition a desired binary wavelet packet tree is obtained. Various WP filterbank tree structures can be derived depending on application of interest. Wavelet features are extracted using Daubachies wavelet of order 4 (db4) [57]. Increaing the order of the mother wavelet may provide better results at expense of increased computational complexity.

\subsubsection{Mel Filter like WP Decomposition}

Farooq et.al.,[20] introduced 24-band Mel like Wavelet Packet Cepstral Features (WMFCC) The sound frequency $f_{c}$ is mapped to the mel frequency $f_{m e l}$ according to the following equation

$$
f_{m e l}=2595 \log _{10}\left(1+\frac{f_{c}}{700}\right)
$$

A frame size of $25 \mathrm{msec}$ with a frame ovelap of $15 \mathrm{msec}$ was used to derive the WMFCC. Intially the speech frames are subjected to preemphasis followed by windowing operation using Hamming window. Initially a balanced three level wavelet packet tree structure is derived. Here, the frequency axis is subdivided into eight subbands each of $1 \mathrm{KHz}$ The low frequency subband in the range 0$1 \mathrm{KHz}$ is again subjeted to three level balanced decomposition to get eight subbands each having a bandwidth of $125 \mathrm{~Hz}$. Which is almost close to $100 \mathrm{~Hz}$ Mel-filter. The subband with frequency range is decomposed into two level balanced WP coefficients, giving four subbands each having a bandwidth of $250 \mathrm{~Hz}$. The subbands in the range $1-1.25 \mathrm{KHz}$ and $1.25-1.5 \mathrm{KHz}$ are decomposed again, resulting in four subbands same bandwidth i.e., $250 \mathrm{~Hz}$. The subband of $3-$ $4 \mathrm{KHz}$ frequency range is again processed by level decomposition, resulting in two subbands of $3-3.5 \mathrm{KHz}$ and $3.5-4 \mathrm{KHz}$ respectively. The frequency bands with ranges $4-5 \mathrm{KHz}, 5-6 \mathrm{KHz}, 6-7 \mathrm{KHz}$, and \&$8 \mathrm{KHz}$ are retained as it is. This results in 24-band Mel scale resembeled WP filter. The bandwidth of the 24 frequency bands 
resulting after WP Decomposition does not exactly follow Mel scale[20] (see Table 1).

Table 1 Comparision of frequency bands of 24-band Mel scale filters and Wavelet Packet sub-band

\begin{tabular}{ccccccccc}
\hline Filters & $\begin{array}{c}\text { Mel } \\
\text { Scale }\end{array}$ & $\begin{array}{c}\text { Wavelet } \\
\text { Subband }\end{array}$ & Filters & $\begin{array}{c}\text { Mel } \\
\text { Scale }\end{array}$ & $\begin{array}{c}\text { Wavelet } \\
\text { Subband }\end{array}$ & Filters & $\begin{array}{c}\text { Mel } \\
\text { Scale }\end{array}$ & $\begin{array}{c}\text { Wavelet } \\
\text { Subband }\end{array}$ \\
\hline 1 & 100 & 125 & 9 & 900 & 1125 & 17 & 2639 & 2750 \\
\hline 2 & 200 & 250 & 10 & 1000 & 1250 & 18 & 3031 & 3000 \\
\hline 3 & 300 & 375 & 11 & 1149 & 1375 & 19 & 3482 & 3500 \\
\hline 4 & 400 & 500 & 12 & 1320 & 1500 & 20 & 4000 & 4000 \\
\hline 5 & 500 & 625 & 13 & 1516 & 1750 & 21 & 4595 & 5000 \\
\hline 6 & 600 & 750 & 14 & 1741 & 2000 & 22 & 5278 & 6000 \\
\hline 7 & 700 & 875 & 15 & 2000 & 2250 & 23 & 6063 & 7000 \\
\hline 8 & 800 & 1000 & 16 & 2297 & 2500 & 24 & 6954 & 8000 \\
\hline
\end{tabular}

The frequency axis is divided with the intention of matching it to frequency response of the Mel scale. The 24-band wavelet packet sub-bands resemble 24-band Mel filters is shown in Figure 5[].

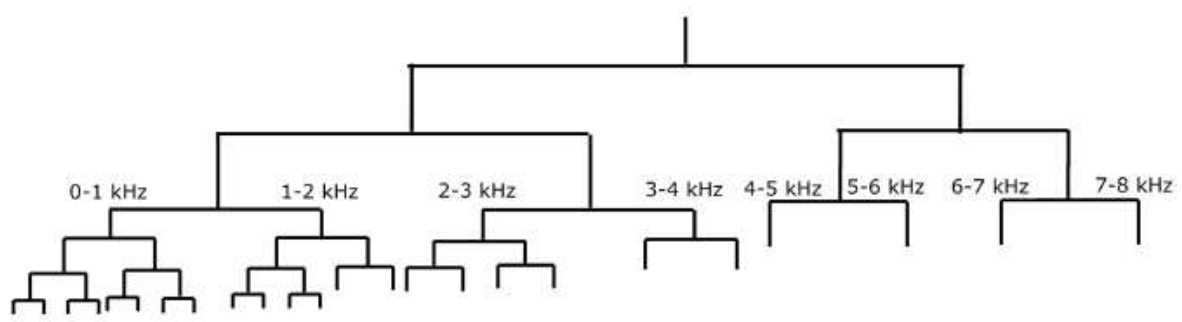

Fig. 5 24-band WP tree based on Mel scale

The energy in each subband is calculated by

$$
\left\langle S_{i}\right\rangle_{k}=\sum \frac{\left|\omega_{\Psi}(x, k)_{i}\right|^{2}}{N_{i}}
$$

where, $\omega_{\Psi}(x, k)_{i}$ is wavelet packet coefficients of the signal $x, i$ is the subband frequency index $(1 \leq i \leq M), k$ indicates the temporal frame and $N_{i}$ is the number of samples in the $i^{\text {th }}$ suband. Similar to MFCC, the 24 energy coefficients are subjected to logarithmic compression. Finally, DCT is applied to all 24 coefficients and only 
first 13 normalized DCT coefficients are considered as WMFCC features. The pictorial representation of the feature extraction process is shown in Figure 6 shown below.

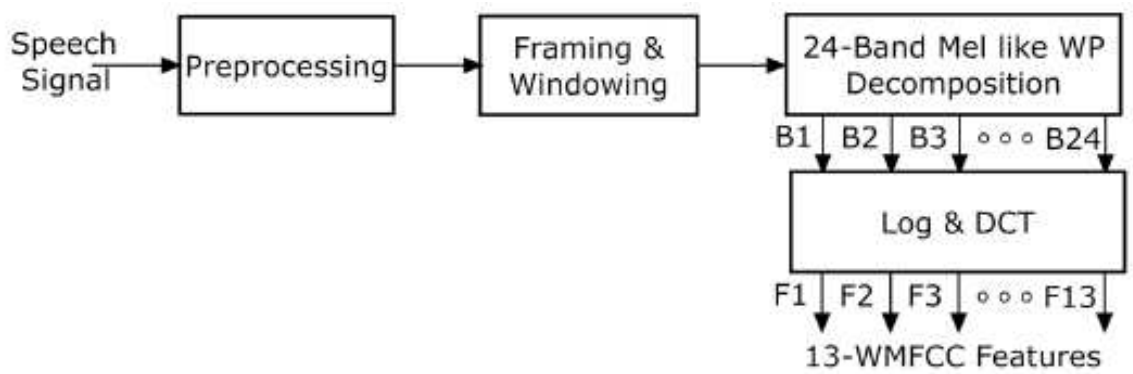

Fig. 6 Steps of acoustic WMFCC feature extraction technique

\subsubsection{Proposed PWP tree structure for feature extraction}

In this work we have proposed a 24-band wavlelet packet tree which is used to obtain the cepstral features. The feature extaction is carried out by proposing a 24-band Wavelet Packet (WP) tree structure after conducting repeated experiments. The WP tree structure shown in Figure 7. is the proposed WP tree structure for obtaining the features.

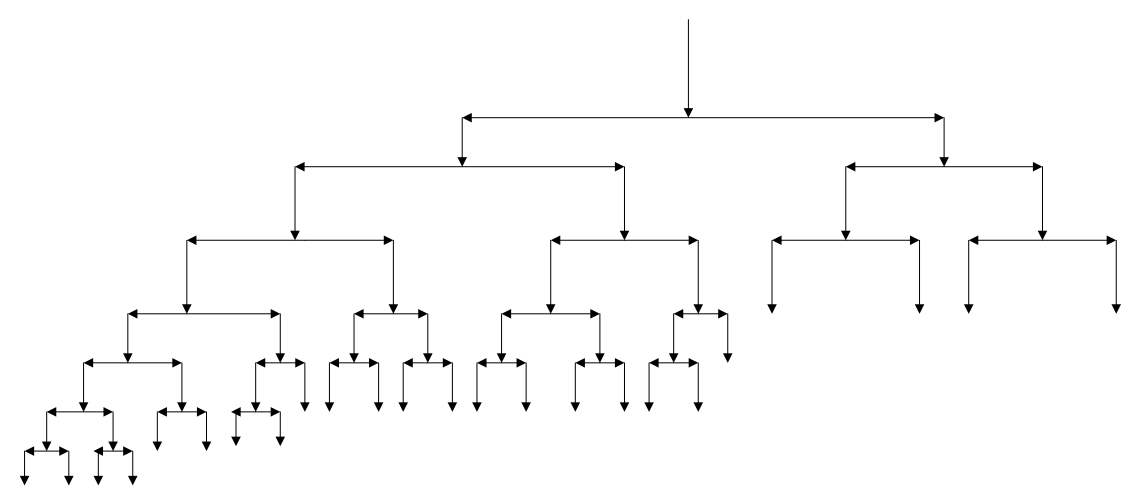

Fig. 7 Proposed 24-band WP tree based on Mel scale

The energy of the 24 band wavelt subbands are calculated. These coefficients are then logarithmically compressed and subjected to Discrete Cosine Transform. Discrete Cosine Transform (DCT) 
basically achieves energy compaction. The outpus of DCT gives 24 coefficients and only first 13 coefficients are used as cepstral coefficients. The Kaldi Toolkit is used to determine the delta and delta delta coefficients to form features of 39-dimension.

\subsubsection{ACOUSTIC MODELS}

The acoustic models are used to map the observed feature matrix with the desired phoneme sequences of the hypothesized sentence. The creation of acoustic models is usually accomplished by using the Hidden Markov Models (HMM).

\subsubsection{LANGUAGE MODELS}

The ASR systems utilize n-gram language models to facilitate the detection of exact word sequence through prediction of $n^{\text {th }}$ word, utilizing $(n-1)$ previous words. Most popular n-gram language models are trigram $(n=3)$ and bigram $(n=2)$ language models.

\subsubsection{RECOGNITION}

The speech recognition task is achieved using Gaussian Mixture Model -Hidden Markov Model (GMM-HMM),Triphones 1, Triphones 2 and Triphones 3 and Deep Neural Network (DNN).

\subsubsection{HIDDEN MARKOV MODEL}

To determine the probability $P\left(\frac{W}{X}\right)$ a 3 -state Markov chain is used here. The 3- state Markov chain is displayed in the Figure 8. In the training phase, probality of system staying in a state $(\pi)$, probability of transition between states(A), and output probabilities (B) are determined applying Baum-Welch Algorithm. The HMM Acoustic Model for each word sequence is defind by using the equation 


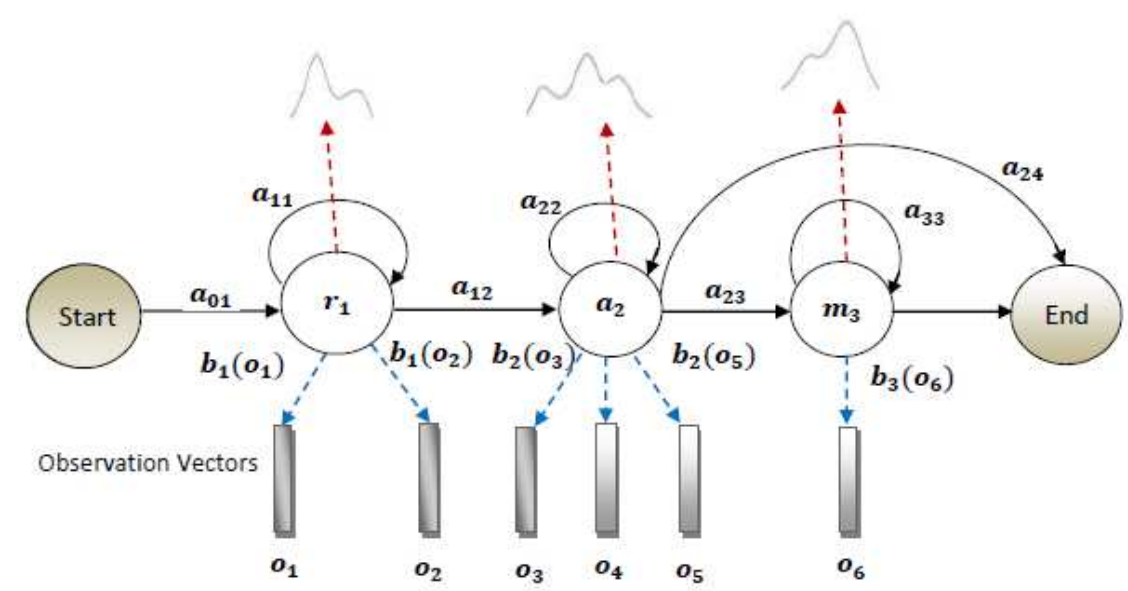

Fig. 8 A 3-state Markov Chain

$$
\lambda=(A, B, \pi)
$$

The log-likelywood of every word sequence is estimated using Viterbi Decoding technique according to the equation

$$
v *=[P(O \mid \lambda v)], \quad 1 \leq v \leq V
$$

$V$ is word length.

\subsubsection{PERFORMANCE ANALYSIS}

The recognition accuracy of any ASR system is determined using the popular metric word error rate and word recognition accuracy [24] given by equations (28) and (29) respectively.

$$
\begin{gathered}
W E R(\%)=\frac{(D+S+I)}{N} \times 100(\%) \\
W R A(\%)=100-W E R(\%)
\end{gathered}
$$

Where $N$ is the total number of words present in the test set and $D, S$ and $I$ are erroes due to deletion, substitution and Insertion respectively. 


\section{DATABASE}

The Kannada speech Database consisting of isolated digits from 0-9, 20 isolated wods and 500 continuous speech sentences which includes combination of read speech and spontaneous speech and native language accents have been used as text script for creating the database. The database consists of 100 speakers. The continuous speech is of 15 hours database. The database is recoreded in the natural environment in the presense of room noise, vehicle noise happening nearby road at a distance of 5 meters from the recording room. The tools used for recording the database is Matlab R2019b software on Dell Laptop. The speech data has been collected at a sampling rate of $16 \mathrm{KHz}, 16-$ bit resolution and Mono recordings. The table indicates the 50 sample sentences from the speech database along with its goolgle transcription. The lexicon is created using Indian Language Symbol Labels version 3 (ILSLv3) prepared by Samudravijay, Indian Institute of Technology, Guwahati. The continuous speech database created here is according to the guidelines suggested by speech research experts from Indian Institute of Technolgy, Guwahati (IITG). The databsase is partitioned into training set and testing set. The $80 \%$ of the database is used for training the Acoustic Models and 20\% of the database is used for testing the model.

The database consists of 3 sets for Kannada Language namely: isolated digits through (0-9), isolated words, Continuous Kannada Speech consisting of Spontaneous Spoken Kannada Sentences also. The database consists of 3 sets for English Language namely: isolated digits (TIMIT) through (0-9), isolated words (TIMIT), Librispeech of Continuous English Speech. The Kannada speech sentences along with their transcription is provided in the Table 2.

Table 2 The Kannada text sentences of the speech data collected and their corresponding transliteration.

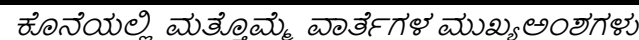

koneyalli mattomme vaartegala mukhyaamsagalu

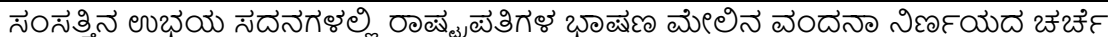
ఆరింభ

samsattina ubhaya sadanagalalli raastrapatigala bhaasanada meelina vandana nirnayada carce aarambha 


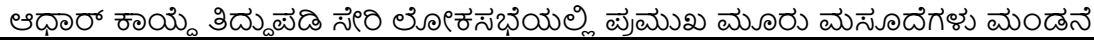
aadhaar kaaide tiddupadi seeri lookasabheyalli pramukha mooru masuudegalu mandane

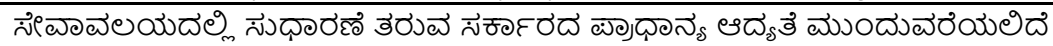

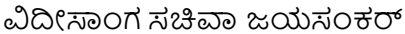

seevaavalayadalli sudaarane taruva sarkaarada praadhaanya aadyate munduvareyalide videesaanga sacivaa Jayasankar

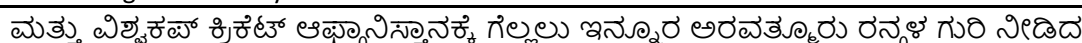
బాంగాల్లిల

mattu visvakap kriket aafgaanistaanakke gellalu innuura aravatmooru rangala guri niidida baanglaadeesa

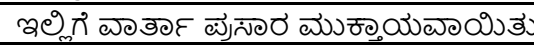

illige vaartaa prasaara muktaayavaayitu

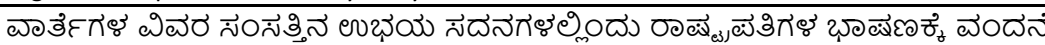

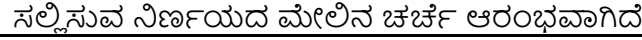

vaartegala vivara samsattina ubhaya sadanagalallindu raastrapatigala bhaasanakke vandane sal-

lisuva nirnayada meelina carce aarambhavaagide

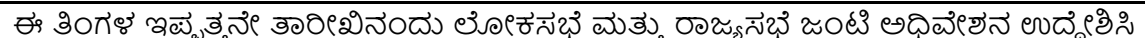

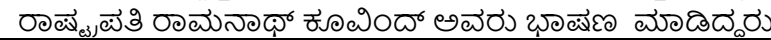

ii tingala ippattane taariikhinandu lookasabhe mattu raajyasabhe janti adhiveesana uddeesisi raastrapati raamanaath koovind avaru bhaasana maadiddaru

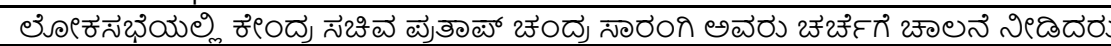
lookasabheyalli keendra saciva prataap candra saarangi avaru carcege caalane niididaru

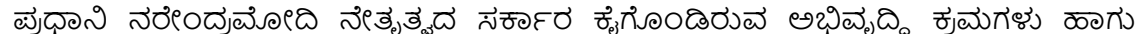
యిలఁజనีగెళ

pradhaani nareendramoodi neetrutvada sarkaara kaigondiruva abhiruddi kramagalu haagu yoojanegala pramu kha amshagalannu ullekhisida prataap candra Sarangi

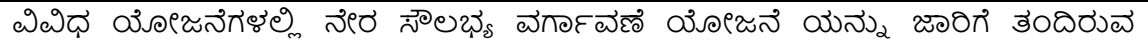

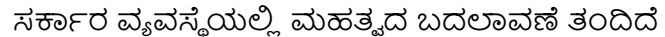

vividha yojanegalalli neera saulabhya vargaavane yojaneyannu jaarige tandiruva sarkaara vyavastheyalli mahatvada badalaavane tandide

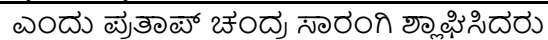

endu prataap candra saarangi shlaaghisidaru

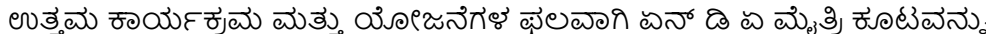

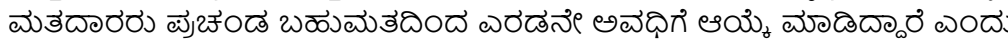
ळе8ిదరు

uttama kaaryakrama mattu yojanegala phalavaagi en di e maitri kuutavannu matadaararu pracanda bahumatadinda eradane avadhige aayke maadiddare endu heelidaru

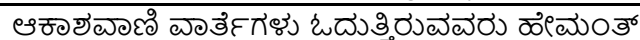

aakaashavaani vaartegalu ooduttiruvavaru heemanth

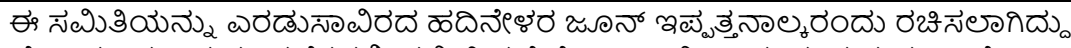

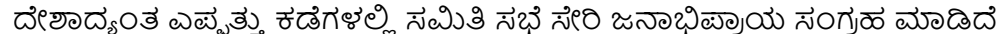

ii samiitiyannu eradsaavrada hadineelara juun ippattnaalkarandu racisalaagiddu deesaadyanta yeppattu kadegalalli samiti sabe seeri janaabipraaya sangraha Maadide

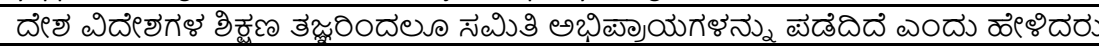
deesa videesagala siksana tagnarindalu samiti abipraayagalannu padedide endu heelidaru

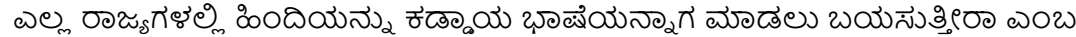

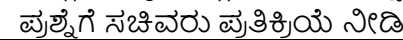

ella raajyagalalli hindiyannu kaddaaya bhaaseyannaaga maadalu bayasuttiira emba prasnege sacivaru pratikriye Nidi 


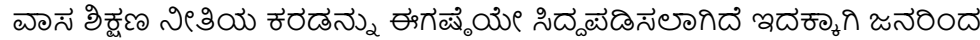

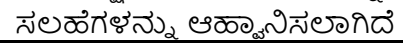

vaasa siksana niitiya karadannu iigastee siddapadisalaagide idakkaagi janarinda salahegalannu aahvaanisalaagide

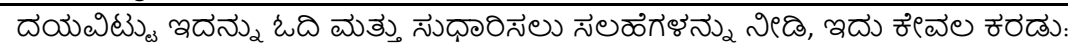

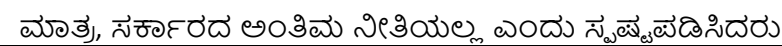

dayavittu idannu odi mattu sudaarisalu salahegalannu niidi idu keevala karadu maatra sarkaarada antima niitiyalla endu spastapadisidaru

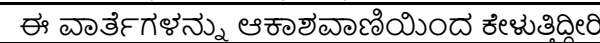

ii vaartegalannu aakaasavaaniyinda keeluttiddiiri

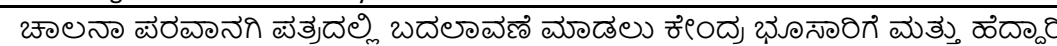

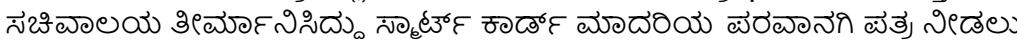
నిదణరిసిదె

caalana paravaanagi patradalli badalaavane maadalu keendra bhuusaarige mattu heddari saci-

vaalaya tiirmaanisiddu smaart kaard maadariya paravaanagi patra niidalu nirdariside

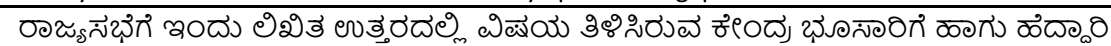

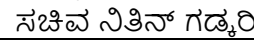

raajyasabhege indu likhita uttaradalli visaya tilisiruva keendra bhuusaarige haagu heddari saciva nitin gadkari

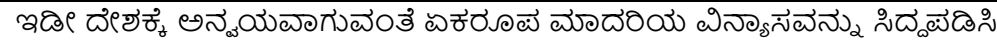

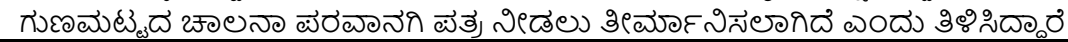

idii deesakke anvayavaaguvante eekaruupa maadariya vinyaasavannu siddapadisi gunamattada caalanaa paravaanagi patra niidalu tiirmaanisalaagide endu tilisiddare

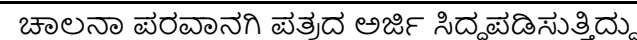

caalanaa paravaanagi patrada arji siddapadisuttiddu

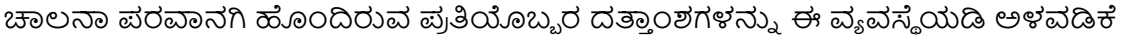
యోడాలాగుంుచుదు

caalana paravaanagi hondiruva pratiyobbara dattaamsagalannu ii vyavasteyadi alavadike maadalaaguvudu

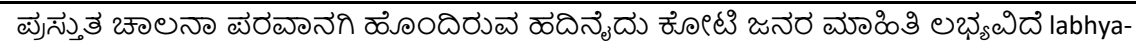
vide

prastuta caalana paravaanagi hondiruva hadinaidu kooti janara maahiti

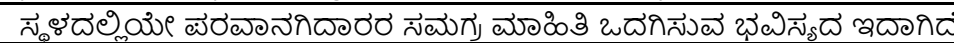

staladalliye paravaanagidaarara samagra maahiti odagisuva bhavisyada idaagide

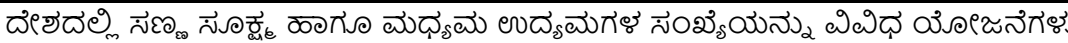

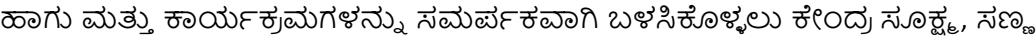

ळలగกల యుధ్య

deesadalli sanna suuksma haagu madhyama udyamagala sankheyannu vivida yoojanegalu haagu mattu kaaryakramagalannu samarpakavaagi balasikollalu keendra suuksma sanna haagu madyama sacivaalaya mundaagide

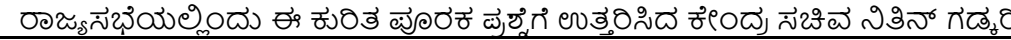

raajyasabheyallindu ii kurita puuraka prasenege uttarisida keendra saciva nitin gadkari

ఈ

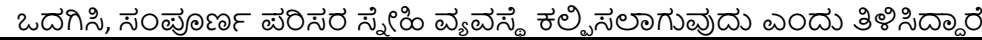

ii valayakke uttama saala saulabhya suukta kausallya mattu aadhunika tantragnaanavannu odagisi sampuurna parisara sneehi vyavaste kalpisalaaguvudu endu tilisiddare

ஸృధానేయుం అభిबృద్దియంతా

लుధానేయుం 3, 


\subsection{KALDI TOOLKIT}

Kaldi is a open source toolkit designed excusively for building Acoustic Models (AMs) and Language Models (LMs) [41]. Kaldi is built using $\mathrm{C}++$ programming language. The Kaldi toolkit can be run in windows as well as Linux based operating systems. But, the support for Linux based Kaldi tasks is very good compared to that of windows. The Table 3 presents the labels for kannada phones using syllable transliteration. There are four Dravidan languages. Kannada, Telugu, Malayalam and Tamil. Kannada is the most popular Dravidan language used in Karnataka state. This language consist of 14 swara (vowels), 32 vyanhana (consonants), 2 part vowel, yogavaahaka (part consonant). The labels used for building the lexicon for phonemes of the Kannada Language is shown in Table 2. Therefore, The Kannada language ASR system is developed by modeling the 46 phonemes. The labels are used from the Indian Speech Sound Label Set (ILSL12) is shown in Table 4. The lexicon for Kannada language is written by using ILSL12 label set shown in Table 5.

Table 3 The labels using syllable transliteration tool (IT3 to UTF-8) for Kannada phones

LABEL SET USING IT3:UTF-8 KANNADA PHONEMES




\begin{tabular}{|c|c|c|c|c|c|c|c|}
\hline $\mathrm{a}$ & Oo & $\mathrm{t}: \mathrm{h}$ & $\mathrm{ph}$ & $\ominus$ & ఓ & $\odot$ & $\vec{\varphi}$ \\
\hline aa & $\mathrm{au}$ & $d$ & $b$ & ఆ & ఔ & $\vec{\omega}$ & బ \\
\hline $\mathrm{i}$ & $k$ & $\mathrm{~d}: \mathrm{h}$ & bh & ఇ & 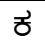 & $\vec{\varphi}$ & భ \\
\hline ii & $\mathrm{kh}$ & nd & $\mathrm{m}$ & ఈ & 2 & ణ & దు \\
\hline $\mathrm{u}$ & $\mathrm{g}$ & $t$ & $y$ & er & $\vec{n}$ & $\overrightarrow{0}$ & యో \\
\hline uu & gh & th & $r$ & ers & $\vec{\psi}$ & థ & $\sigma$ \\
\hline $\mathrm{e}$ & C & $d$ & 1 & $\omega$ & ఒ & $\vec{ద}$ & $e$ \\
\hline ee & $\mathrm{ch}$ & $\mathrm{dh}$ & $v$ & $\omega$ & ఝ & ధౌ & $\vec{\omega}$ \\
\hline ai & $j$ & $n$ & sh & $\varpi$ & జ & $\vec{న}$ & ஏ \\
\hline 0 & $\mathrm{t}:$ & $p$ & $S$ & ఒ & ६ & $\vec{\omega}$ & $\vec{\sim}$ \\
\hline
\end{tabular}

Table 4 The labels used from the Indian Speech Sound Label Set (ILSL12) for Kannada phonemes

\begin{tabular}{|c|c|c|c|c|c|c|c|}
\hline \multicolumn{4}{|c|}{ LABEL SET USING IT3:UTF-8 } & \multicolumn{4}{|c|}{ KANNADA PHONEMES } \\
\hline $\mathrm{a}$ & oo & txh & ph & అ & ఓ & ఠ & $\vec{\varphi}$ \\
\hline aa & au & $\mathrm{dx}$ & $b$ & ఆ & ఔ & $\vec{\omega}$ & బ \\
\hline $\mathrm{i}$ & $\mathrm{k}$ & $\mathrm{dxh}$ & bh & ఇ & 于े & $\vec{\varphi}$ & భ \\
\hline ii & $\mathrm{kh}$ & $\mathrm{nx}$ & $\mathrm{m}$ & ఈ & 2 & ణ & దు \\
\hline $\mathrm{u}$ & g & $\mathrm{t}$ & $\mathrm{y}$ & er & $\vec{n}$ & उ़ & యి \\
\hline uu & gh & th & $r$ & en & $\vec{\psi}$ & ఢ & $\sigma$ \\
\hline e & c & d & I & $\omega$ & ఒろ & దె & $e$ \\
\hline ee & ch & $\mathrm{dh}$ & w & ఏ & ఢ & ధ઼ & $\vec{\omega}$ \\
\hline ai & $\mathrm{j}$ & $n$ & sh & $\varpi$ & జ & నె & ర \\
\hline 0 & $\mathrm{tx}$ & $p$ & $\mathrm{~s}$ & ఒ & ६ & $\vec{\omega}$ & $\vec{\sim}$ \\
\hline
\end{tabular}

Table 5 Dictionary for Kannada language is created by using ILSL12 label set

\begin{tabular}{|c|c|}
\hline TEXT TRANSCRIPTION & LABEL SET USING ILSL12 \\
\hline koneyalli & kone y a llx i \\
\hline mattomme & $\mathrm{mattomme}$ \\
\hline vaartegala & v aarteg a lx \\
\hline mukhyamshagalu & mukhy aa nx s hag a lx u \\
\hline samsattina & s a nx s a tt in a \\
\hline ubhaya & $\mathrm{ubh}$ a y a \\
\hline sadanagalalli & s a d a n a g a lx llx i \\
\hline raastrapatigala & raas trapatiga $1 x$ \\
\hline
\end{tabular}




\begin{tabular}{cc}
\hline bhasanada & b h aa s a nx d a \\
\hline meelina & m ee l i n a \\
\hline vandana & v a n d a n a \\
\hline nirnayada & n i r nx y a d a \\
\hline carce & c a r c e \\
\hline aarambha & aa r a nx b h a \\
\hline vaartegala & v aa r t e g a lx \\
\hline vivara & v i v a r a \\
\hline samsattina & s a nx s a tt i n a \\
\hline ubhaya & u b h a y a \\
\hline sadanagalallindu & s a d a n a g a lx llx i nx d u \\
\hline raastrapatigala & r aa s t r a p a t i g a lx \\
\hline bhaasanakke & b h aa s a nx kk e \\
\hline vandane & v a n d a n e \\
\hline sallisuva & s a llx i s u v a \\
\hline nirnayada & n i r nx y a d a \\
\hline meelina & m ee l i n a \\
\hline carce & c a r c e \\
\hline aarambhavaagide & aa r a nx b h a v aa g i d e \\
\hline
\end{tabular}

The dictionary is created by using ILSL12. Figure 10 represents the block diagram of the proposed features.

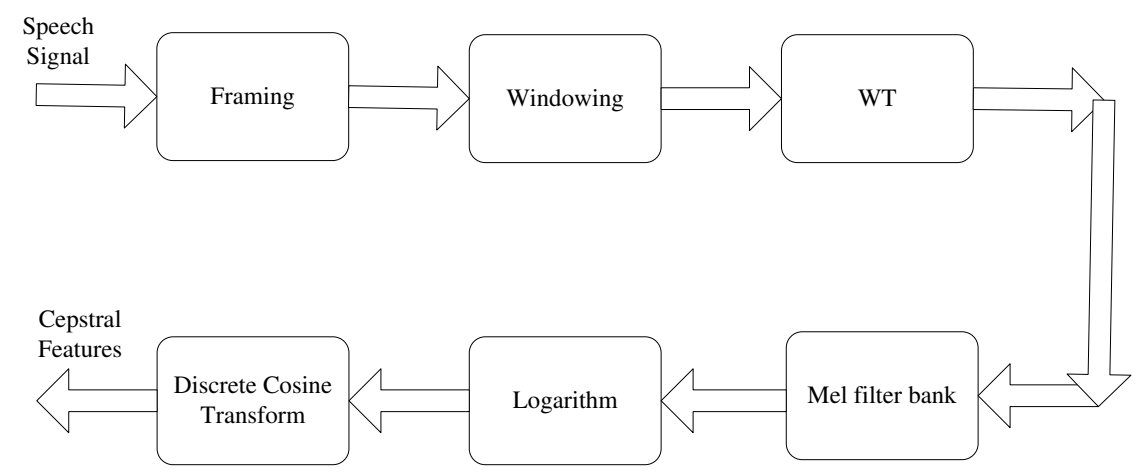

Fig. 10 Block diagram of proposed features 


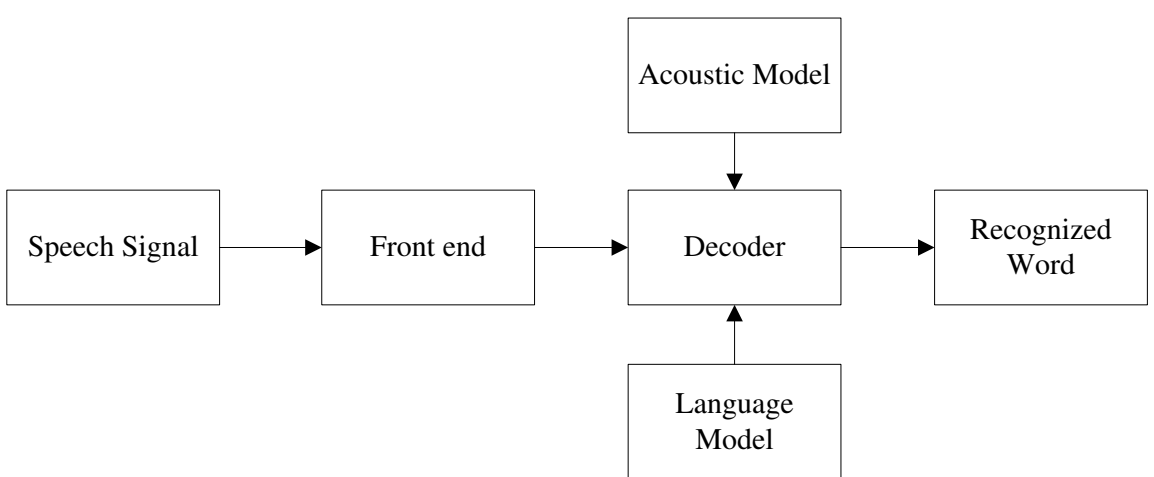

Fig. 11 ASR system architecture

The general architecture of ASR system is shown in Figure 11.

The Table 6 provides the details of parameters used for acoustic modelling. The acoustic models are generated at Monophones, Triphones 1 and Triphones3 levels with number of jobs 3. The parameters used to develop Acoustic Model are as follows:

Table 6 Parameters of the Acoustic Models

\begin{tabular}{llll}
\hline Patameters Specific to Acoustic Model & Triphone 1 & Triphone2 & Triphone3 \\
\hline Number of Leaves & 2500 & 2500 & 2500 \\
\hline Number of Gaussian & 20000 & 20000 & 20000 \\
\hline S.
\end{tabular}

\section{RESULTS}

The results of developed ASR system is presented in this section for Monophones, Triphones1, Triphones2, Triphones3 and DNN-HMM Phoneme Models. The Table 7 gives the WER details for the Kannada Isolated digit recognition task. The pictorial representation of Table 7 are presented in Figure 12.

Table 7 Kannada Isolated digit recognition

\begin{tabular}{ccccc}
\hline SET1_DIGITS & Features-> & MFCC & PLP & Proposed \\
\hline \multirow{3}{*}{ WER } & Mono & 4.80 & 7.20 & 20.00 \\
\cline { 2 - 5 } & Tri 1 & 2.80 & 5.60 & 10.40 \\
\cline { 2 - 5 } & Tri 2 & 5.60 & 8.00 & 8.80 \\
\hline
\end{tabular}




\begin{tabular}{ccccc}
\hline Tri 3 & 3.60 & 3.20 & 2.80 \\
\cline { 2 - 4 } & DNN-HMM & 4.40 & 4.00 & 2.80 \\
\hline
\end{tabular}

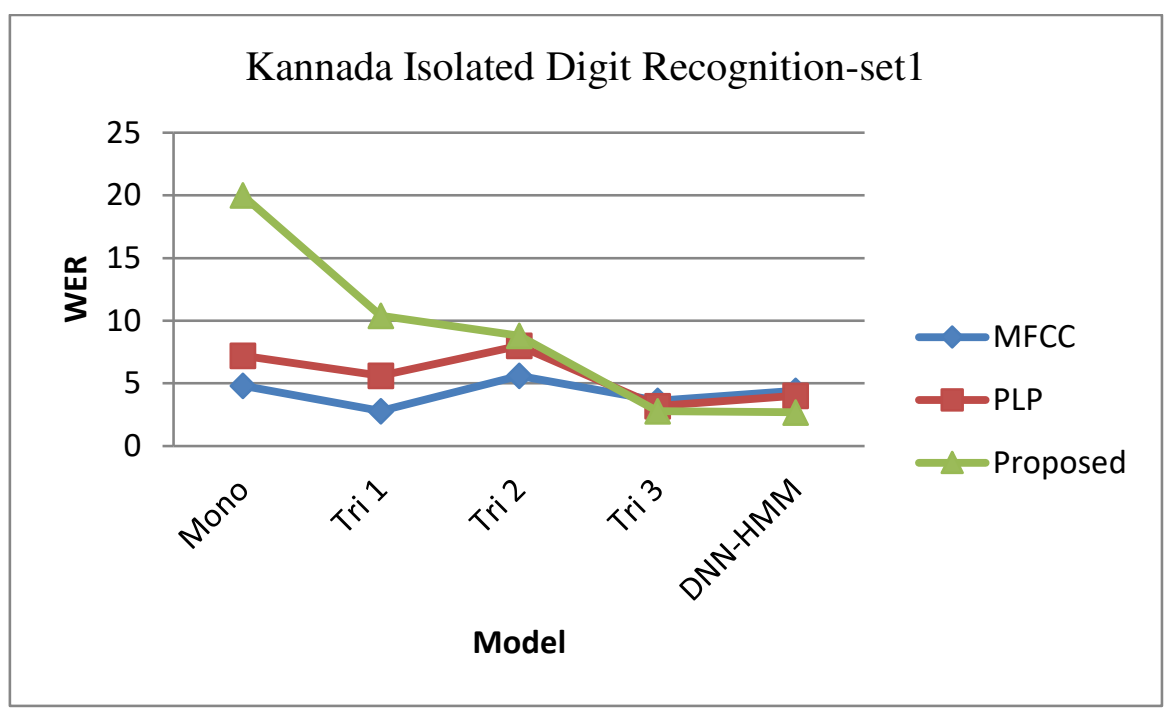

Fig. 12 Comparision of WER for Kannada Isoalted Digit Recognition over MFCC, PLP, Proposed features

The Kannada isolated word recognition results and the corresponding graph are presented in Table 8 and Figure 13 respectively.

Table 8 Kannada Isolated Word recognition

\begin{tabular}{ccccc}
\hline SET2_WORDS & Features & MFCC & PLP & Proposed \\
\hline \multirow{3}{*}{ WER } & Mono & 2.25 & 2.80 & 2.77 \\
\cline { 2 - 5 } & Tri 1 & 1.30 & 2.46 & 3.08 \\
\cline { 2 - 5 } & Tri 2 & 1.23 & 1.52 & 1.85 \\
\cline { 2 - 5 } & Tri 3 & 0.92 & 1.30 & 1.23 \\
\cline { 2 - 5 } & DNN-HMM & 0.92 & 1.23 & 0.31 \\
\hline
\end{tabular}




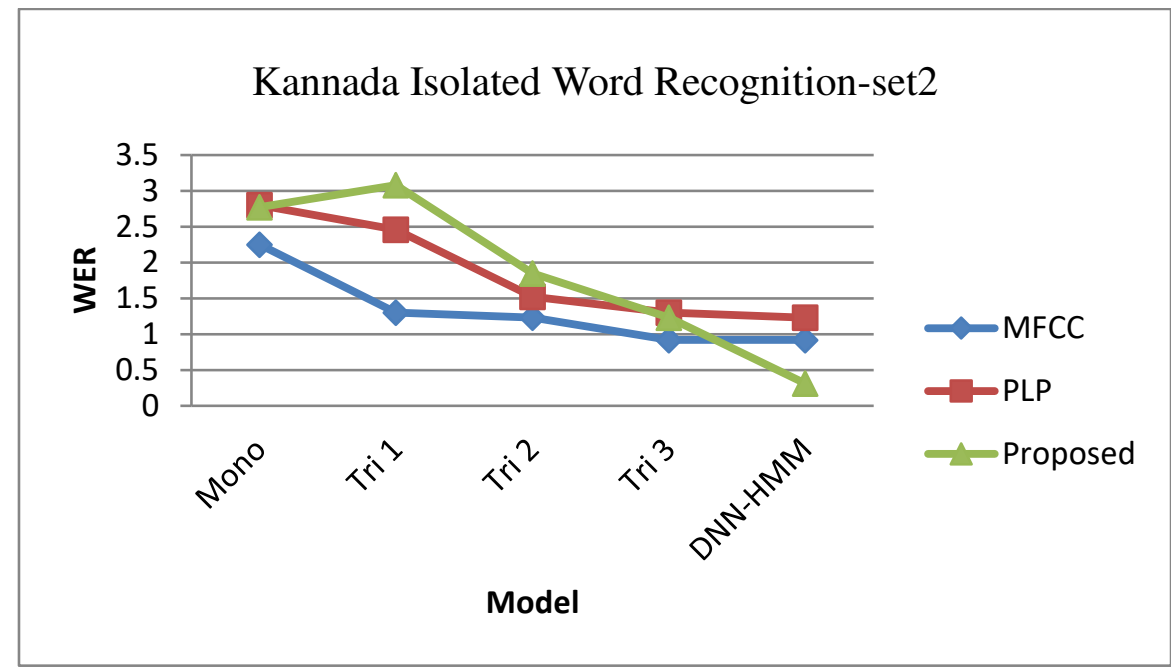

Fig. 13 Comparision of WER for Kannada Isoalted Word Recognition over MFCC, PLP, Proposed features

Table 9 Continuous Kannada speech recognition using MFCC, PLP, Proposed features

\begin{tabular}{cllll}
\hline SET3_SENTENCES & Features & MFCC & PLP & Proposed \\
\hline WER & Mono & 07.37 & 06.39 & 16.20 \\
\cline { 2 - 5 } & Tri 1 & 08.07 & 07.35 & 08.96 \\
\cline { 2 - 5 } & Tri 2 & 12.23 & 11.49 & 14.09 \\
\cline { 2 - 5 } & Tri 3 & 08.01 & 07.17 & 07.01 \\
\cline { 2 - 5 } & DNN-HMM & 06.06 & 06.33 & 04.27 \\
\hline
\end{tabular}




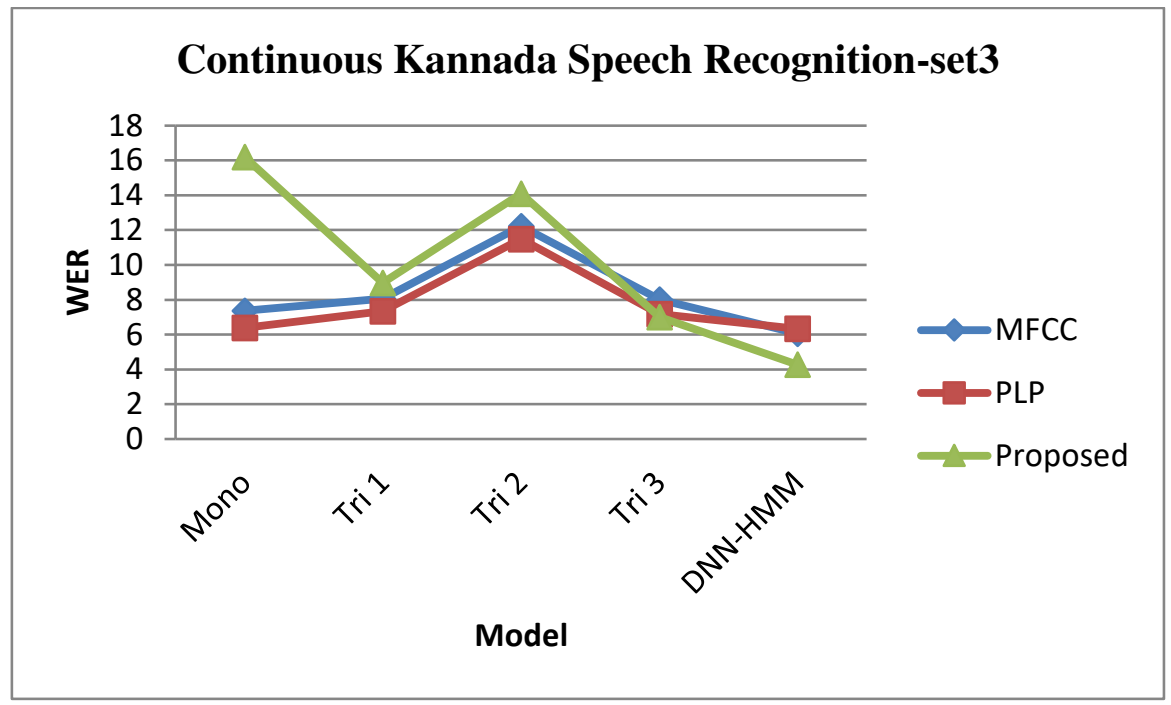

Fig. 14 Comparision of WER for Kannada Continuous Speech Recognition over MFCC, PLP, Proposed features

The WER details for Continuous Kannada speech recognition for the speech data collected in uncontrolled conditions are presented in Table 9 and Figure 14 respectively. In all the three sets of Kannada language a slight improvement in the performance can be observe with the proposed features over the MFCC and PLP features for DNN-HMM classifier.

Table 10 English Isolated digit recognition

\begin{tabular}{lllll}
\hline SET4_DIGITS & Features & MFCC & PLP & Proposed \\
\hline \multirow{2}{*}{ WER } & Mono & 4.70 & 7.30 & 20.23 \\
\cline { 2 - 5 } & Tri 1 & 2.60 & 5.70 & 10.40 \\
\cline { 2 - 5 } & Tri 2 & 5.64 & 8.00 & 08.82 \\
\cline { 2 - 5 } & Tri 3 & 2.23 & 2.28 & 02.20 \\
\cline { 2 - 5 } & DNN-HMM & 2.00 & 2.00 & 01.23 \\
\hline
\end{tabular}




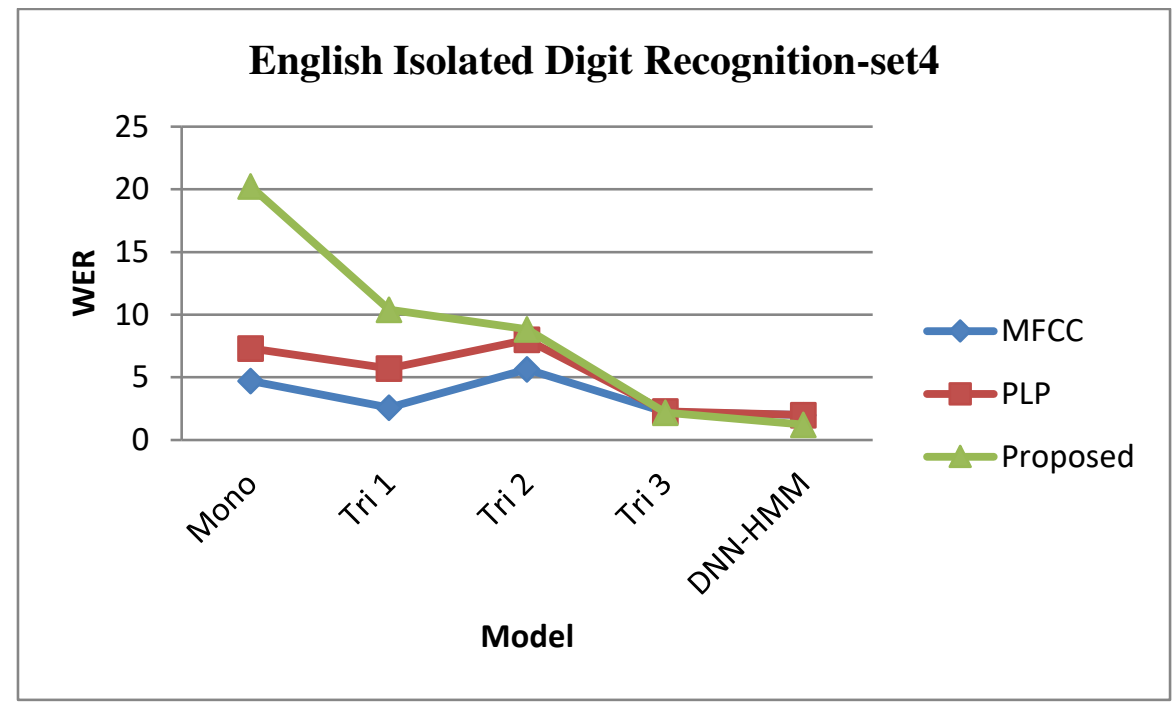

Fig. 15 Comparision of WERs for English Isolated Digit Recognition over MFCC, PLP, Proposed features

The proposed features are also experimented with the isolated digits and isolated words extracted from the TIMIT database. The Table 10 and Figure 15 describes the performance of proposed features over the MFCC and PLP features. The Table 11 and Figure 16 describe the performance of the proposed features over the MFCC and PLP features.A slight improvement in the performance can be observed in Table 11.

Table 11 English Isolated word recognition

\begin{tabular}{lcccc}
\hline SET5_WORDS & Features & MFCC & PLP & Proposed \\
\hline \multirow{2}{*}{ WER } & Mono & 1.50 & 4.25 & 4.75 \\
\cline { 2 - 5 } & Tri 1 & 1.39 & 4.00 & 3.25 \\
\cline { 2 - 5 } & Tri 2 & 1.31 & 3.50 & 1.50 \\
\cline { 2 - 5 } & Tri 3 & 1.25 & 2.25 & 1.00 \\
\cline { 2 - 5 } & DNN-HMM & 1.01 & 1.00 & 0.75 \\
\hline
\end{tabular}




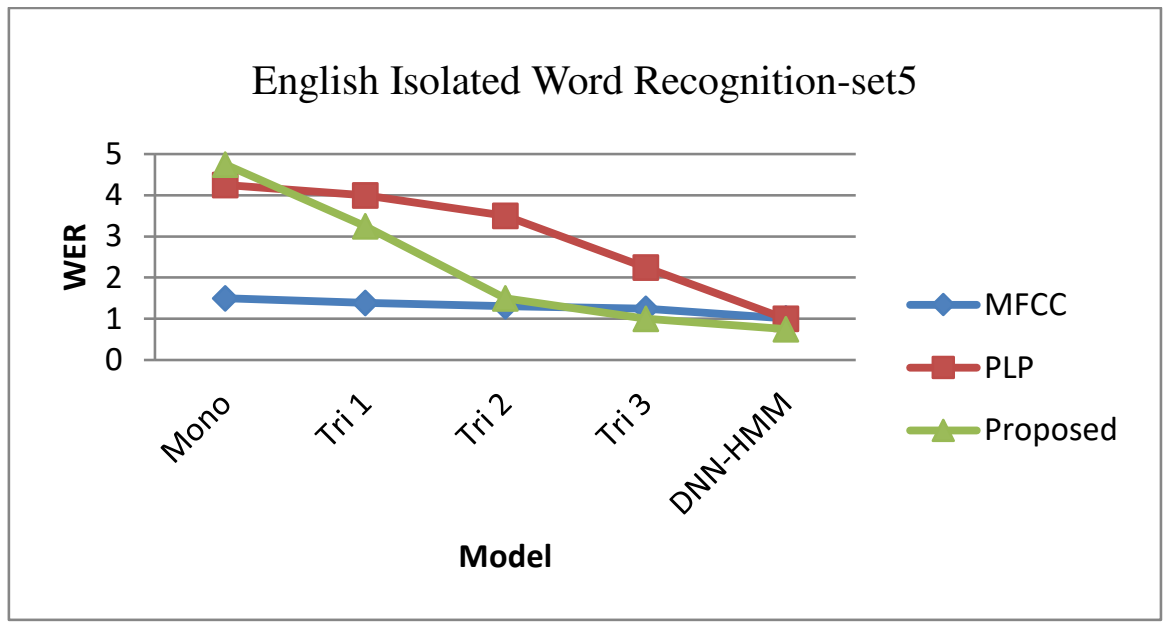

Fig. 16 Comparision of WERs for English Isolated Word Recognition over MFCC, PLP, Proposed features

The proposed features are also experimented with standard Librispeech corpus of 08 hours. A little improvement in the performance can be observed for the proposed features over the baseline features such as MFCC and PLP. The WER details are recoreded in the Table 12 and Figure 17.

Table 12 English Continuous speech recognition recognition

\begin{tabular}{clccc}
\hline SET6 SENTENCES & Features & MFCC & PLP & Proposed \\
\hline \multirow{2}{*}{ WER } & Mono & 62.04 & 61.17 & 77.21 \\
\cline { 2 - 5 } & Tri 1 & 38.75 & 37.72 & 69.95 \\
\cline { 2 - 5 } & Tri 2 & 35.49 & 35.40 & 40.33 \\
\cline { 2 - 5 } & Tri 3 & 30.86 & 30.29 & 30.26 \\
\cline { 2 - 5 } & DNN-HMM & 30.68 & 35.20 & 30.42 \\
\hline
\end{tabular}

The Proposed ASR system is also tested with the unseen data consisting of 512 sentences of different combinations of words. A sample of 20 sentences are shown in the Table 13 and the results of the experiment are included in the Table 14 


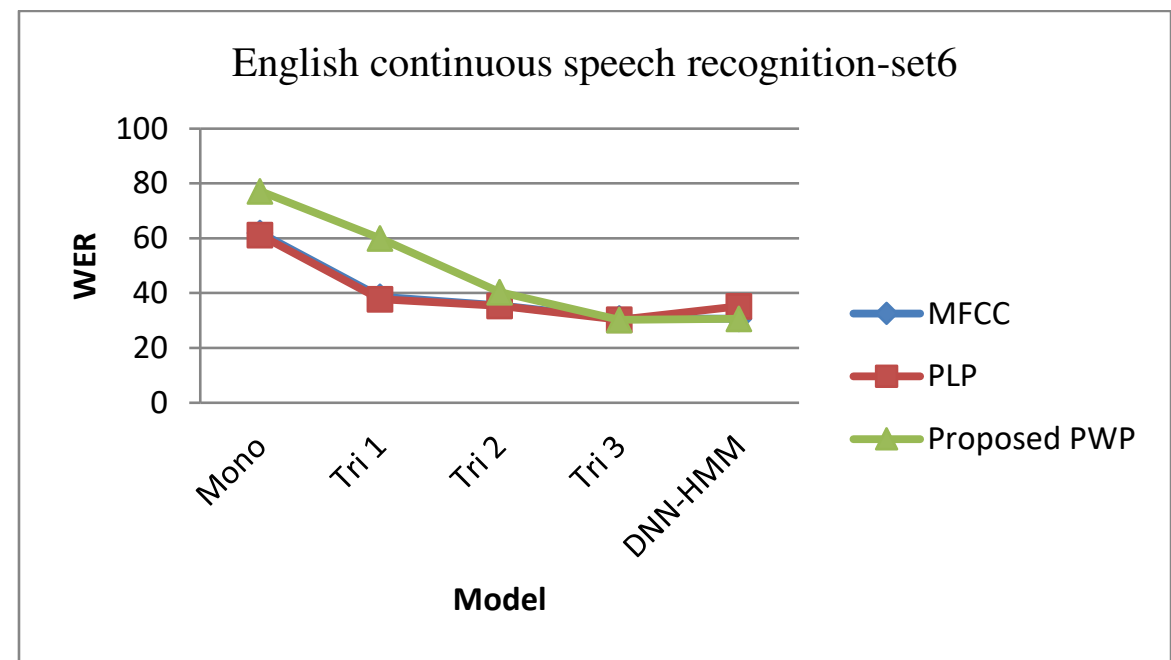

Fig. 17 Comparision of WERs for English Continuous Speech Recognition over MFCC, PLP, Proposed features

Table 14 Comparison of WER among MFCC, PLP and proposed features on Kannada database

\begin{tabular}{ccccc}
\hline TASKS (53-55) & Features & MFCC & PLP & Proposed \\
\hline \multirow{3}{*}{ WER } & Mono & 07.80 & 07.40 & 10.40 \\
\cline { 2 - 5 } & Tri 1 & 04.40 & 04.00 & 05.60 \\
\cline { 2 - 5 } & Tri 2 & 03.20 & 03.80 & 02.80 \\
\hline & Tri 3 & 02.80 & 03.20 & 02.40 \\
\hline DNN-HMM & 02.60 & 03.00 & 02.20 \\
\hline
\end{tabular}

\section{CONCLUSION}

The ASR work carried out in this paper are as follows.

- We have experimented the conventional as well as proposed feature extraction technique over Monophone Models, Triphones1, Triphones2, triphones3 and DNN-HMM.

- The database consists of 3 sets for Kannada Language namely: isolated digits through (0-9), isolated words, Continuous Kan- 
nada Speech consisting of Spontaneous Spoken Kannada Sentences also.

- The database consists of 3 sets for English Language namely: isolated digits (TIMIT) through (0-9), isolated words (TIMIT), Librispeech of Continuous English Speech.

- In the experiments conducted over isolated digits and words taken from collected data of Kannada Language and from TIMIT data, the proposed features achieved significant improvement in the performance over the baseline features such as MFCC, PLP.

- For the experiments on collected Kannada Continuous Speech and Librispeech the proposed features are shown to perform better than the conventional features such as MFCC and PLP features.

- The Proposed ASR system is tested with the unseen data of 512 sentences and the performance on this test data set reveals that the proposed system performs better than the conventional features such as MFCC and PLP features.

\section{DECLARATION}

This work is not funded by any of the funding agencies. The authors comply with the ethical standards of the journal. The authors also declare that they have no conflict of interest. Author's would like to express their gratitude to Management, Principal, HODECE, Vidyavardhaka College of Engineering, Mysuru for their constant support, motivation and encouragement in completing this work.

Table 13 Continuous Kannada speech sentences (unseen data) used for only for testing Kannada ASR system.

\begin{tabular}{|c|c|c|c|}
\hline $\begin{array}{l}\text { Sl. } \\
\text { No. }\end{array}$ & $\begin{array}{l}\text { Kannada } \\
\text { Sentence }\end{array}$ & Kannada Transcription & $\begin{array}{l}\text { English } \\
\text { Translation }\end{array}$ \\
\hline 1. & నెద్కు జిలదెనేద్ డెయాణణ & $\begin{array}{l}\text { Nam'ma jīvanada prayāṇa tum- } \\
\text { bā kașta }\end{array}$ & $\begin{array}{l}\text { The journey of our life is } \\
\text { very difficult }\end{array}$ \\
\hline 2. & ఆరిఠeగ్య మొఖ్య దందు & Ārōgya mukhya endu kathe bari & Tell the story that health \\
\hline
\end{tabular}




\begin{tabular}{|c|c|c|c|}
\hline & రిథా బరి & & is important \\
\hline 3. & $\begin{array}{l}\text { నిన్న మొందినే డృయాణణ } \\
\text { ఏనాల ఇరిలి }\end{array}$ & $\begin{array}{l}\text { Ninna mundina prayāṇa ēnē } \\
\text { irali }\end{array}$ & $\begin{array}{l}\text { whatever your next } \\
\text { journey }\end{array}$ \\
\hline & 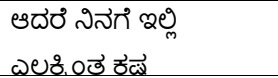 & $\begin{array}{l}\text { Ādare ninage illi ellakkinta } \\
\text { kașta }\end{array}$ & but it's hard for you here \\
\hline 5. & $\begin{array}{l}\text { ఆదెర నెంబిశే నినెగก } \\
\text { తుంబా డొఖ్య }\end{array}$ & $\begin{array}{l}\text { Ādare nambike ninage tumbā } \\
\text { mukhya }\end{array}$ & $\begin{array}{l}\text { But faith is very im- } \\
\text { portant to you }\end{array}$ \\
\hline 6. & $\begin{array}{l}\text { మొందినే డెయోాణ } \\
\text { యోాదుదు ఎందు బరి }\end{array}$ & $\begin{array}{l}\text { Mundina prayāṇa yāvudu endu } \\
\text { bari }\end{array}$ & $\begin{array}{l}\text { Write about the next } \\
\text { journey }\end{array}$ \\
\hline & $\begin{array}{l}\text { నిన్న ఝొందినే శాలసే ఉనేe } \\
\text { ఇరాలి }\end{array}$ & Ninna mundina kelasa ēnē irali & Whatever your next job \\
\hline & 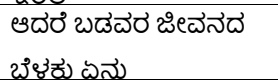 & $\begin{array}{l}\text { Ādare baḍavara jīvanada beḷaku } \\
\text { ēnu }\end{array}$ & $\begin{array}{l}\text { But what is the light of } \\
\text { the life of the poor }\end{array}$ \\
\hline & $\begin{array}{l}\text { అదెర్ జిఱదెన బరి అసైత్య } \\
\text { పెడి }\end{array}$ & Avara jīvana bari asatya kathe & His life is simply untrue \\
\hline & $\begin{array}{l}\text { ఆదెరి నేన్న, కాథి ఇల్లి } \\
\text { దొ2. }\end{array}$ & Ādare nanna kathe illi mukhya & $\begin{array}{l}\text { But my story is im- } \\
\text { portant here }\end{array}$ \\
\hline & 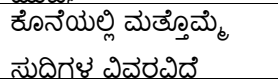 & $\begin{array}{l}\text { Koneyalli mattomme vaartegala } \\
\text { vivara }\end{array}$ & $\begin{array}{l}\text { At the end is the detail } \\
\text { of the news once again }\end{array}$ \\
\hline 12. & 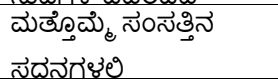 & $\begin{array}{l}\text { Mattomme samsattina } \\
\text { sadanagalalli }\end{array}$ & $\begin{array}{l}\text { Once again in the houses } \\
\text { of parliament }\end{array}$ \\
\hline 13. & దృతేణగిళ డిదెర ఆరాంభ & Vaartegala vivara aarambha & $\begin{array}{l}\text { The beginning of the } \\
\text { news detail }\end{array}$ \\
\hline 14. & దోతినే దొఖ్య అంరేగెళు & Bhaasanada mukhyaamshagalu & $\begin{array}{l}\text { The main elements of } \\
\text { talk }\end{array}$ \\
\hline & 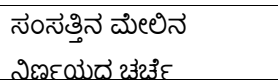 & $\begin{array}{l}\text { Samsattina meelina nirnayada } \\
\text { carce }\end{array}$ & $\begin{array}{l}\text { The debate on the reso- } \\
\text { lution on parliament }\end{array}$ \\
\hline 16. & 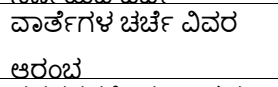 & $\begin{array}{l}\text { Varthegala carce vivara aaram- } \\
\text { bha }\end{array}$ & $\begin{array}{l}\text { Beginning of the discus- } \\
\text { sion of the news }\end{array}$ \\
\hline 17. & 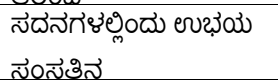 & $\begin{array}{l}\text { Sadanagalallindu ubhaya sam- } \\
\text { sattina }\end{array}$ & $\begin{array}{l}\text { Dual parliament in the } \\
\text { house }\end{array}$ \\
\hline 18. & 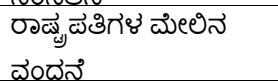 & $\begin{array}{l}\text { Raastrapatigala meelina van- } \\
\text { dane }\end{array}$ & Salute to the president \\
\hline 19. & 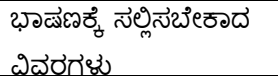 & Bhaasanakke sallisuva vivara & $\begin{array}{l}\text { Details to submit to the } \\
\text { speech }\end{array}$ \\
\hline 20. & 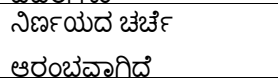 & $\begin{array}{l}\text { Nirnayada carce aarambhavaa- } \\
\text { gide }\end{array}$ & $\begin{array}{l}\text { The resolution debate } \\
\text { has begun }\end{array}$ \\
\hline
\end{tabular}

\section{REFERENCES}

1. Bharali, S.S. \& Kalita, S.K. "Speech recognition with reference to Assamese language using novel fusion technique", Int J Speech Technol 2018, 21: 251 https://doi.org/10.1007/s10772-018-9501-1

2. Hassan, F., Khan, M. S. A., Kotwal, M. R. A., \& Huda, M. N. Gender independent bangia automatic speech recognition. In International Conference on Informatics, Electronics \& Vision (ICIEV-2012). 
3. Muslima, U., \& Islam, M. B. Experimental framework for melscaled LP based Bangla speech recognition. In 2013 IEEE 16th international conference on computer and information technology (ICCIT), Khulna 2014, (pp. 56-59).

4. Pruthi, T., Saksena, S., \& Das, P. K. Swaranjali: Isolated word recognition for Hindi language using VQ and HMM. In international conference on multimedia processing and systems (ICMPS), Chennai, 2000.

5. Kumar, K., \& Aggarwal, R. K. Hindi speech recognition system using HTK. International Journal of Computing and Business Research, 2011, 2(2), 2229-6166.

6. Kumar, K., Aggarwal, R. K., \& Jain, A. A Hindi speech recognition system for connected words using HTK. International Journal of Computational Systems Engineering, 2012, 1(1), 25-32.

7. Kurian, C., \& Balakrishnan, K. Speech recognition of Malayalam numbers. In IEEE World Congress on Nature \& Biologically Inspired Computing, 2009. NaBIC 2009, Coimbatore (pp. 1475-1479).

8. Bansal, P., Dev, A., \& Jain, S. B. Automatic speaker identification using vector quantization. Asian Journal of Information Technology, 2007, 6(9), 938-942

9. Balleda, J., Murthy, H. A., \& Nagarajan, T. Language identification from short segments of speech. In Interspeech 2000, Beijing.

10. Kumar, R., \& Singh, M. Spoken isolated word recognition of Punjabi language using dynamic time warp technique. In Information systems for Indian languages. Berlin: Springer, 2011, (pp. 301-301)

11. Senoussaoui, M., Kenny, P., Dehak, N., \& Dumouchel, P. An I-vector extractor suitable for speaker recognition with both microphone and telephone speech. In Odyssey, Brno 2010.

12. Dipanjan Nandi, Debadatta Pati, K. Sreenivasa Rao, Implicit processing of LP residual for language identification, Computer Speech \& Language, Volume 41, 2017, Pages 68-87, ISSN 0885-2308, https://doi.org/10.1016/j.csl.2016.06.002

13. Kim, C., \& Stern, R. M. (2012). Power-normalized cepstral coefficients (PNCC) for robust speech recognition. In 2012 IEEE International Conference on Acoustics, Speech and Signal Processing (ICASSP) (pp. 4101-4104). IEEE. https ://doi.org/10.1109/ICASSP.2012.62888 20.

14. Li, J., Deng, L., Gong, Y., \& Haeb-Umbach, R. (2014). An overview of noise-robust automatic speech recognition. IEEE/ACM Transactions on Audio, Speech, and Language Processing, 22(4), 745-777. https ://doi.org/10.1109/TASLP .2014.23046 37.

15. Mukherjee, H., Obaidullah, S. M., Santosh, K. C., Phadikar, S., \& Roy, K. (2018). Line spectral frequency-based features and extreme learning machine for voice activity detection from audio signal. International Journal of Speech Technology. https ://doi.org/10.1007/s1077 2-018-9525-6.

16. Bouguelia, M.-R., Nowaczyk, S., Santosh, K. C., \& Verikas, A. (2017). Agreeing to disagree: Active learning with noisy labels without crowdsourcing. International Journal of Machine Learning and Cybernetics, 9(8), 1307-1319. https ://doi.org/10.1007/s13042-017-0645-0. 
17. Davis, S., \& Mermelstein, P. (1980). Comparison of parametric representations for monosyllabic word recognition in continuously spoken sentences. IEEE Transactions on Acoustics, Speech, and Signal Processing, 28(4), 357-366. https ://doi.org/10.1109/TASSP .1980.1163420.

18. Farooq, O., Datta, S., \& Shrotriya, M. C. (2010). Wavelet sub-band based temporal features for robust Hindi phoneme recognition. International Journal of Wavelets, Multiresolution and Information Processing, 08(06), 847-859. https ://doi.org/10.1142/S0219691310003845.

19. Ganchev, T., Fakotakis, N., \& Kokkinakis, G. (2005). Comparative evaluation of various MFCC implementations on the speaker verification task. In Proceedings of the SPECOM (pp. 191-194).

20. Farooq, O., \& Datta, S. (2001). Mel filter-like admissible wavelet packet structure for speech recognition. IEEE Signal Processing Letters, 8(7), 196-198. https ://doi.org/10.1109/97.928676.

21. Grigoryan, A. M. (2005). Fourier transform representation by frequency-time wavelets. IEEE Transactions on Signal Processing, 53(7), 2489-2497. https ://doi.org/10.1109/TSP.2005.849180.

22. Biswas, A., Sahu, P. K., Bhowmick, A., \& Chandra, M. (2014a). Feature extraction technique using ERB like wavelet sub-band periodic and aperiodic decomposition for TIMIT phoneme recognition. International Journal of Speech Technology, 17(4), 389-399. https ://doi.org/10.1007/s1077 2-014-9236-6.

23. Biswas, A., Sahu, P. K., \& Chandra, M. (2016). Admissible wavelet packet sub-band based harmonic energy features using ANOVA fusion techniques for Hindi phoneme recognition. IET Signal Processing, 10(8), 902-911. https ://doi.org/10.1049/iietspr.2015.0488.

24. Steffen, P., Heller, P. N., Gopinath, R. A., \& Burrus, C. S. (1993). Theory of regular M-band wavelet bases. IEEE Transactions on Signal Processing, 41(12), 3497-3511. https ://doi.org/10.1109/78.258088.

25. Vetterli, M., \& Herley, C. (1992). Wavelets and filter banks: Theory and design. IEEE Transactions on Signal Processing, 40(9), 2207-2232. https ://doi.org/10.1109/78.15722 1

26. Lin, T., Xu, S., Shi, Q., \& Hao, P. (2006b). An algebraic construction of orthonormal M-band wavelets with perfect reconstruction. Applied Mathematics and Computation, 172(2), 717-730. https ://doi.org/10.1016/j.amc.2004.11.025.

27. Pollock, S., \& Cascio, IL (2007). Non-dyadic wavelet analysis. In Optimisation, econometric and financial analysis (pp. 167-203). Berlin: Springer. https ://doi.org/10.1007/3-540-36626-1_9.

28. Chiu, C.-C., Chuang, C.-M., \& Hsu, C.-Y. (2009). Discrete wavelet transform applied on personal identity verification with ECG signal. International Journal of Wavelets, Multiresolution and Information Processing, 07(03), 341-355. https ://doi.org/10.1142/S0219691309002957.

29. Rajoub, B., Alshamali, A., \& Al-Fahoum, A. S. (2002). An efficient coding algorithm for the compression of ECG signals using the wavelet transform. IEEE Trans- 
actions on Biomedical Engineering, 49(4), 355-362. https ://doi.org/10.1109/10.991163.

30. Tabibian, S., Akbari, A., \& Nasersharif, B. (2015). Speech enhancement using a wavelet thresholding method based on symmetric Kullback-Leibler divergence. Signal Processing, 106, 184-197. https ://doi.org/10.1016/J.SIGPR O.2014.06.027.

31. Zao, L., Coelho, R., \& Flandrin, P. (2014). Speech enhancement with EMD and hurst-based mode selection. IEEE Transactions on Audio, Speech and Language Processing, 22(5), 899-911. https://doi.org/10.1109/TASLP .2014.23125 41.

32. Adeli, H., Zhou, Z., \& Dadmehr, N. (2003). Analysis of EEG records in an epileptic patient using wavelet transform. Journal of Neuroscience Methods, 123(1), 69-87. https ://doi.org/10.1016/S0165-0270(02)00340 -0.

33. Ocak, H. (2009). Automatic detection of epileptic seizures in EEG using discrete wavelet transform and approximate entropy. Expert Systems with Applications, 36(2), 2027-2036. https ://doi.org/10.1016/J.ESWA.2007.12.065.

34. Biswas, A., Sahu, P. K., \& Chandra, M. (2014b). Admissible wavelet packet features based on human inner ear frequency response for Hindi consonant recognition. Computers \& Electrical Engineering,40(4), 1111-1122. https ://doi.org/10.1016/J.COMPE LECENG.2014.01.008.

35. Leggetter, C. J., \& Woodland, P. C. (1995). Maximum likelihood linear regression for speaker adaptation of continuous density hidden Markov models. Computer Speech \& Language, 9(2), 171-185.

36. Gales, M. (2000). Cluster adaptive training of hidden Markov models. IEEE transactions on speech and audio processing, 8(4), 417-428.

37. Karpov, A., et al. (2014). Large vocabulary Russian speech recognition using syntactico-statistical language modeling. Speech Communication, 56, 213-228

38. Daubechies, Ingrid. Ten lectures on wavelets. Society for industrial and applied mathematics, 1992.

39. http://www.iitg.ac.in/cseweb/tts/tts/Assamese/transliteration/Indic\%20Language $\% 20$ Transliteration\%20Tool\%20(IT3\%20to\%20UTF-8)_11.html

40. http://www.iitg.ac.in/samudravijaya/tutorials/ILSL_V3.2.pdf

41. Povey, Daniel, Arnab Ghoshal, Gilles Boulianne, Lukas Burget, Ondrej Glembek, Nagendra Goel, Mirko Hannemann et al. "The Kaldi speech recognition toolkit." In IEEE 2011 workshop on automatic speech recognition and understanding, no. CONF. IEEE Signal Processing Society, 2011.

42. Thimmaraja G. Yadava, H. S. Jayanna. "A spoken query system for the agricultural commodity prices and weather information access in Kannada language", International Journal of Speech Technology, 2017

43. "Performance of Isolated and Continuous Digit Recognition System using Kaldi Toolkit", International Journal of Recent Technology and Engineering, 2019

44. Thimmaraja Yadava G, H S Jayanna. "Creation and Comparison of Language and Acoustic Models Using Kaldi for Noisy and Enhanced Speech Data", International Journal of Intelligent Systems and Applications, 2018 
45. P. S. Praveen Kumar, G. Thimmaraja Yadava, H. S. Jayanna. "Continuous Kannada Speech Recognition System Under Degraded Condition", Circuits, Systems, and Signal Processing, 2019

46. Biswas, Astik, P.K. Sahu, Anirban Bhowmick, and Mahesh Chandra. "Hindi phoneme classification using Wiener filtered wavelet packet decomposed periodic and aperiodic acoustic feature", Computers \& Electrical Engineering, 2015.

47. Mahadevaswamy, D J Ravi, Performance of Isolated and Continuous Digit Recognition System using Kaldi Toolkit, 2019 International Journal of Recent Technology and Engineering

48. Mahadevaswamy and D. J. Ravi, "Performance analysis of adaptive wavelet denosing by speech discrimination and thresholding," 2016 International Conference on Electrical, Electronics, Communication, Computer and Optimization Techniques (ICEECCOT), Mysuru, 2016, pp. 173-178, doi: 10.1109/ICEECCOT.2016.7955209.

49. Mahadevaswamy and D. J. Ravi, "Performance analysis of adaptive wavelet denosing by speech discrimination and thresholding," 2016 International Conference on Electrical, Electronics, Communication, Computer and Optimization Techniques (ICEECCOT), Mysuru, 2016, pp. 173-178, doi: 10.1109/ICEECCOT.2016.7955209

50. Mahadevaswamy and D. J. Ravi, "Performance Analysis of LP Residual and Correlation Coefficients based Speech Seperation Front End," 2017 International Conference on Current Trends in Computer, Electrical, Electronics and Communication (CTCEEC), Mysore, 2017, pp. 328-332, doi: 10.1109/CTCEEC.2017.8455039

51. Geethashree A, D J Ravi, “Automatic Segmentation of Kannada Speech for Emotion Conversion", Journal of Advanced Research in Dynamical and Control Systems.

52. Geethashree A, D J Ravi, "Modification of Prosody for Emotion Conversion using Gaussian Regression Model”, 2019 International Journal of Recent Technology and Engineering

53. Geethashree A., Ravi D.J. (2018) Kannada Emotional Speech Database: Design, Development and Evaluation. In: Guru D., Vasudev T., Chethan H., Kumar Y. (eds) Proceedings of International Conference on Cognition and Recognition. Lecture Notes in Networks and Systems, vol 14. Springer, Singapore.

54. Basavaiah, J., \& Patil, C. M. (2020). Human activity detection and action recognition in videos using convolutional neural networks. Journal of Information and Communication Technology, 19(2), 157-183.

55. Basavaiah, J., \& Anthony, A. A. (2020). Tomato Leaf Disease Classification using Multiple Feature Extraction Techniques. Wireless Personal Communications. doi:10.1007/s11277-020-07590-x 